\title{
Is There Any Association Between the Efficacy of Imaging Techniques and the Age of the Patient in the Diagnosis of Acute Appendicitis?
}

\author{
Sinem Doğruyol', Vehbi Özaydın', Burcu Azapoğlu Kaymak', Fatma Sarı Doğan', Seda Nur Bağdigen', Togay Evrin² \\ 'Department of Emergency Medicine, Medeniyet University Göztepe Training and Research Hospital, İstanbul, Turkey \\ 2Department of Emergency Medicine, Ufuk University School of Medicine, Dr. Rıdvan Ege Training and Research Hospital, Ankara, Turkey
}

Cite this article as: Doğruyol S, Özaydın V, Azapoğlu Kaymak B, Sarı Doğan F, Bağdigen S, Evrin T. Is There Any Association Between the Efficacy of Imaging Techniques and the Age of the Patient in the Diagnosis of Acute Appendicitis? Eurasian J Emerg Med 2017; 16: 123-7

\begin{abstract}
Aim: In this study, we aimed to assess whether there is any difference between the time and effectiveness seen in the diagnostic stage of acute appendicitis when an appropriate imaging method is selected for the patients in different age groups.

Materials and Methods: During the 6-month period between October 1, 2015, and April 1, 2016, we retrospectively reviewed the files of patients who visited our emergency clinic, which is a third-step emergency department of a university hospital, and who then underwent operations at our hospital. Patients were evaluated according to their age: Group 1, 40 years and younger; Group 2, 40-60 years; Group 3, 60 years and older.

Results: In this study, 97 patients (59.1\%) were male and 67 patients (40.9\%) were female. Their ages ranged from 19 to 86 years (mean age, $36.7 \pm 14.7$ years). The percentage of patients who underwent only ultrasonography (US) was 52.3\% in the first age group, 39.5\% in the second age group, and $0.0 \%$ in the third age group $(p<0.0001)$. The rates of patients who underwent only computerized tomography (CT) were $15.3 \%$ in the first age group, $28.9 \%$ in the second age group, and $60 \%$ in the third age group $(p<0.0001)$. There was a statistically significant difference between the sensitivities of CT and US by age group ( $p<0.001$ ).
\end{abstract}

Conclusion: We believe that US should be the first method to be preferred in young and uncomplicated cases and that CT should be preferred in elderly patients with atypical presentations.

Keywords: Acute abdomen, computerized tomography, ultrasonography

\section{Introduction}

Acute appendicitis (AA) is one of the most common causes that requires an operation in patients visiting hospital with an abdominal pain (1). These cases are usually seen in patients under 50 years of age and peak in the second and third decades (2). The developments in imaging methods that support the diagnosis of AA have reduced the number of patients who were operated unnecessarily and shortened the waiting period in the complicated cases before surgery. Although this is such a common case about which many studies have been done, there are still debates about the diagnostic methods for AA.
Ultrasonography (US) and computerized tomography (CT) are the two basic imaging modalities used in AA; they are still the most important and valid diagnostic tools. Even though CT is considered more successful for diagnosis in many studies, we can never abandon US because of the radiation exposure aspect of CT $(3,4)$. To determine the imaging method that is used during diagnosis according to patient history and symptoms will also increase the effectiveness of the method.

In this study, selected imaging modalities in the diagnostic process of cases operated on the basis of an AA diagnosis and whose histopathologic examinations were compatible with AA were retrospectively reviewed. The aim of this study was to examine whether 


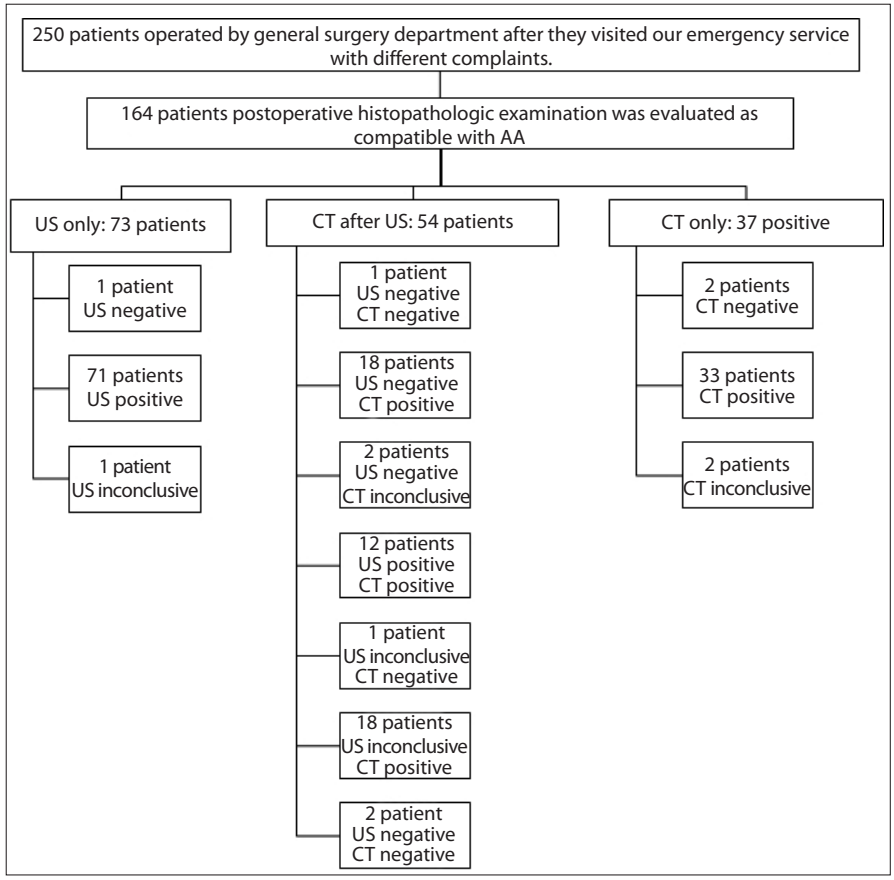

Figure 1. Study flowchart: patient selection and the results of imaging methods

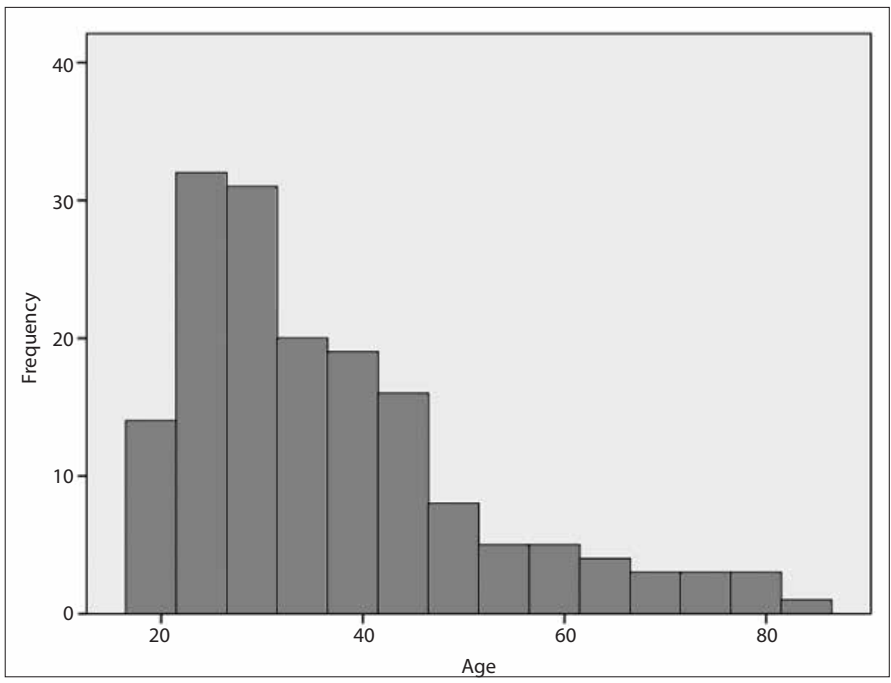

Figure 2. The age distribution of acute appendicitis patients. When the age distribution of the patients was analyzed with KolmogorovSmirnov test, because the skewness-kurtosis values were calculated between -1.5 and +1.5 , this dataset fit normal distribution

there is any difference between the time and effectiveness seen in the diagnosis stage of AA when an appropriate imaging method is selected for patients from different age groups.

\section{Materials and Methods}

During the 6-month period between October 1, 2015, and April 1,2016 , we retrospectively reviewed the files of the persons who visited our emergency clinic, a third-step emergency department of a university hospital, and then operated at our hospital. The ethics committee's approval for the study was given by the same institution.

\section{Patient selection}

The case files of 164 persons whose postoperative histopathologic examination was evaluated as compatible with AA and who had at least one result of an imaging method (US or/and CT) during diagnosis at emergency service records. Of the 250 patients older than 18 years of age who were operated by the general surgery department of our hospital after they visited our emergency service with different complaints were reviewed (Figure 1). The official radiology report of the imaging method of all these cases was available in our hospital system. The patients were evaluated according to their age, gender, imaging method performed with AA preliminary diagnosis in emergency department; result of AA in terms of radiology report; and time interval between the first visit and imaging times (minutes). Patients were grouped according to their age: Group 1, 40 years and younger, Group 2, 40-60 years, Group 3, 60 years and older. Patients were assessed on the basis of the imaging methods: US only; CT only; and US and CT. Imaging methods were examined for significant differences in the activities at specific age ranges.

\section{US examination}

US examination was performed applying a printed sonography technique for AA using 3.5-MHz convex and a 5-7.5 MHz linear probe and followed by a full abdominal sonographic examination. The ultrasounds planned with AA were evaluated by a senior assistant physician or a specialist physician who had completed at least two years in the radiology clinic of our hospital. According to the US report, cases with a thickness of more than $6 \mathrm{~mm}$, no peristalsis, compression anechoic fluid collection, appendicolith, and US McBurney findings were accepted as US-positive. The cases in which appendicitis was not seen or seen as normal were reported as negative. The cases in which a free fluid was detected in the perianal region, the cecum wall was edematous, and the perianal mesenteric lymph nodes were seen were reported as suspicious $(5,6)$.

\section{CT examination}

The CTs in our study included the abdominal section between the L2 vertebra and the symphysis pubis. All patients were administered contrast material (1-mL Ultravist 300, $50 \mathrm{cc}$ vial containing $0.623 \mathrm{~g}$ iopromide in an aqueous solution) intravenously (IV) at a rate of $0.8-1 \mathrm{~mL} / \mathrm{s}$. After $60 \mathrm{~s}$, the patients were scanned by helical CT using a $5 \mathrm{~mm}$ slice thickness and $5-\mathrm{mm}$ table motion. These $\mathrm{CT}$ images were evaluated and reported by a senior assistant physician or a specialist physician who had completed at least two years in our hospital radiology clinic. CT positivity criteria (at least two of the three criteria must be present) were: anterior-posterior appendicitis diameter greater than $7 \mathrm{~mm}$; an increase in heterogeneity and attenuation of periapical fatty tissue; and an increase in wall thickness more than 2 $\mathrm{mm}$ compared to other intestinal segments. In the patients who met only one criterion, the CT was evaluated as unclear. The appendix that was smaller than $6 \mathrm{~mm}$, had no inflammation sign in the surrounding structures, and a normal wall thickness was classified as negative in $\mathrm{CT}(7)$.

\section{Statistical analysis}

IBM Statistical Package for the Social Sciences 20.0 (IBM SPSS Statistics; Armonk, NY, USA) was used for the statistical analyses of the data. The normal distribution suitability of continuous variables 
Table 1. CT and US comparison results in the acute appendicitis diagnosis

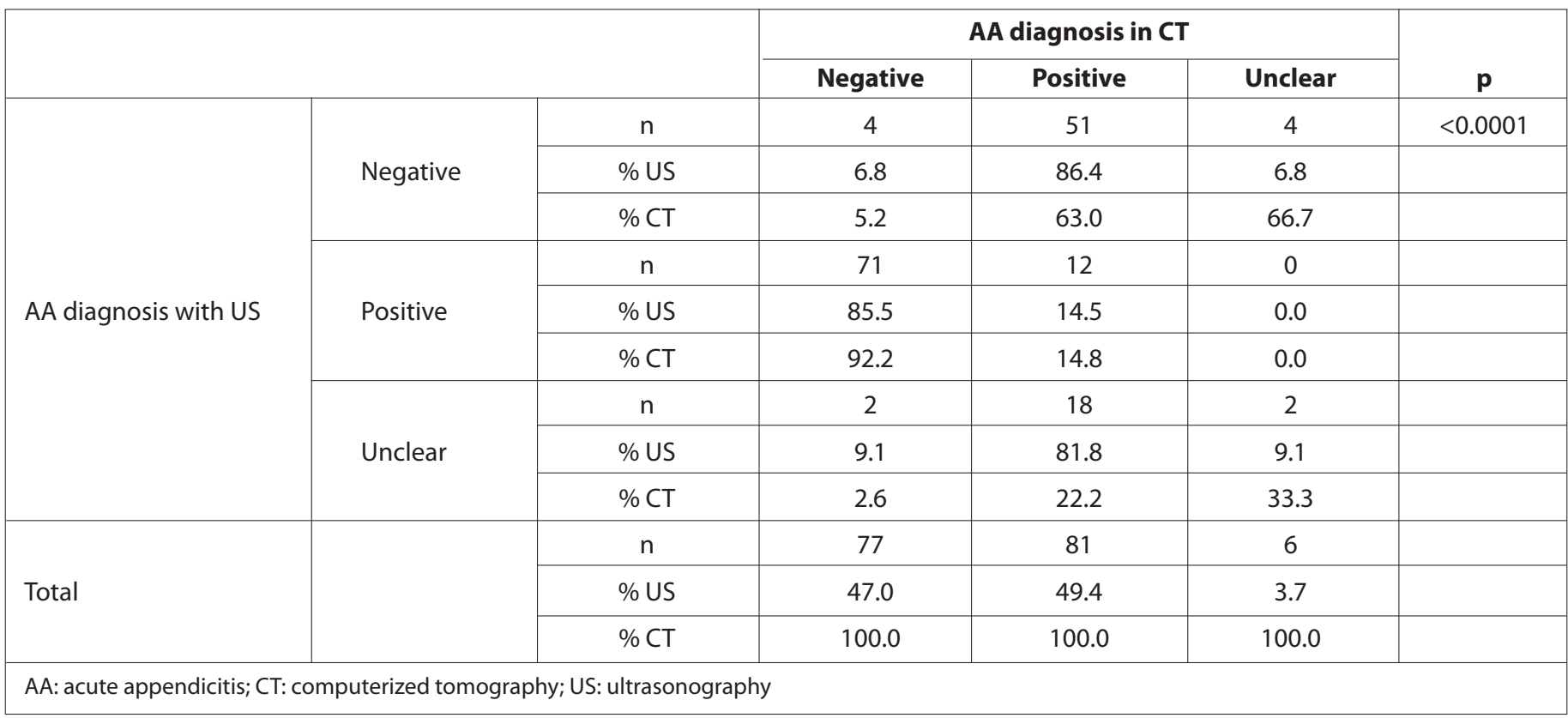

Table 2. CT and US sensitivity rates by age group

\begin{tabular}{|l|c|c|c|c|c|}
\hline & & $\mathbf{1}^{\text {st }}$ age group & $\mathbf{2}^{\text {nd }}$ age group & $\mathbf{3}^{\text {rd }}$ age group & Significant difference \\
\hline \multirow{2}{*}{ Sensitivity } & CT & $42.3 \%$ & $52.6 \%$ & $93.3 \%$ & + \\
\cline { 2 - 6 } & US & $55.0 \%$ & $47.4 \%$ & $26.7 \%$ & + \\
\hline
\end{tabular}

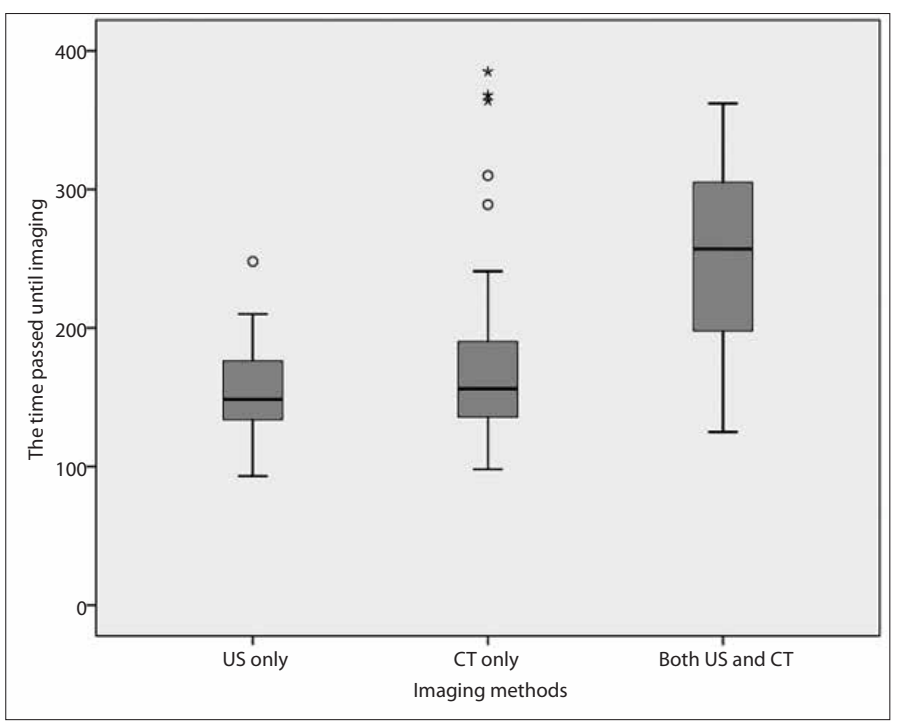

Figure 3. Boxplots comparing the time passed until imaging stratified by imaging methods. There was a significant difference in the data showing the time passed until imaging between the US only group and both US and CT group $(p=0.000)$

CT: computerized tomography; US: ultrasonography

was measured by the Kolmogorov-Smirnov test. The Mann-Whitney $\mathrm{U}$ was used for the comparison of the mean of the related binary groups of continuous variables without normal distribution, and Kruskal-Wallis test was used for the comparison of the mean of more than two groups. The chi-square test was used to compare categor- ical variables. The descriptive statistics were given as percent, frequency, mean, and standard deviation. Significance was tested at a level of alpha equal to 0.05 .

\section{Results}

In this study, 97 patients (59.1\%) were male and 67 patients (40.9\%) were female. The ages ranged from 19 to 86 years (mean age, $36.7 \pm 14.7$ years). When the age distribution of the patients was analyzed with Kolmogorov-Smirnov test, because the skewness-kurtosis values were calculated between -1.5 and +1.5 , this dataset fit normal distribution (Figure 2). According to age groups, the most patients were observed in the first age group (111 patients, 67.7\%) and then second age group (38 patients, $23.2 \%$ ) and followed by third age group (15 patients, 9.1\%).

In our study, US was used to diagnose $77.4 \%$ (127 patients) of the patients. US application percentages in different groups were $84.7 \%$ in the first age group, $71.1 \%$ in the second age group, and $40 \%$ in the third age group $(p<0.0001)$. The rate of patients undergoing only US because it was preferred during diagnosis was $52.3 \%$ in the first age group, $39.5 \%$ in the second age group, and $0.0 \%$ in the third age group $(\mathrm{p}<0.0001)$.

In all, $55.5 \%$ of our patients (91 patients) were evaluated with CT: $47.7 \%, 60.5 \%$, and $100.0 \%$ of the patients in the first, second, and third groups, respectively $(p<0.001)$. The proportion of patients for whom only CT was preferred in the diagnosis process was $15.3 \%$, $28.9 \%$, and $60 \%$ in the first, second, and third age groups, respectively $(p<0.0001)$. When the patients for whom both imaging methods 
were used were categorized according to their age groups, no statistically significant difference was observed between groups.

When the results of the imaging methods were compared, of the 59 patients with a negative US result, CT was positive in 51, negative in four, and unclear in four patients. Of the 83 patients with a positive US diagnosis, 12 had a positive CT scan and 71 had a negative CT scan result. We found that CT was positive in $81.8 \%$ of the cases who ended up with an unclear US, and it was negative and unclear in the remaining four (18.2\%) patients (Table 1). The difference between the positive diagnostic decisions for the patients was statistically significant $(p<0.0001)$.

When the patients included in the study were evaluated on the basis of the age group, there was no statistically significant difference between the sensitivity of CT and US $(p<0.001)$ (Table 2$)$.

The time passed until imaging was calculated as $151 \pm 27 \mathrm{~min}$ in the US group only, $180 \pm 74 \mathrm{~min}$ in the CT group only, and $253 \pm 59 \mathrm{~min}$ in both the US and CT groups (Figure 3). There was a significant difference in the data showing the time passed until imaging between the US group and both US and CT groups $(p=0.000)$.

The data showing the time passed until imaging according to different age groups were $187 \pm 65 \mathrm{~min}, 185 \pm 69 \mathrm{~min}$, and $242 \pm 79 \mathrm{~min}$ in first, second, and third age groups, respectively. A 55-min difference was detected between first and third age groups, in which confidence intervals $(\mathrm{Cl})$ were statistically significant $(\mathrm{p}=0.009,95 \% \mathrm{Cl}$, 11.42-98.60). A 56.6-min difference was detected between second and third age groups; this difference was statistically significant as well $(p=0.017,95 \% \mathrm{Cl}, 8.33-104.95)$.

\section{Discussion}

In this study, it was found that making an examination based on age group in the diagnosis of AA provides high sensitivity and accelerates the diagnosis. The incidence of AA is around 9\% in Western societies, and its incidence is increasing in both developed and developing countries $(8,9)$. Early diagnosis and treatment of this disease is important. Pre-hospital and hospital delays should be prevented. US, $\mathrm{CT}$, and diagnostic scoring systems are available to assist the clinician to prevent hospital delays (10-12). However, despite these developments, the diagnosis of AA may not be as easy as it assumed.

The incidence of AA at an early age is higher than that in the elderly population $(13,14)$. However, the presentation of these diseases in younger patients may be different from that in middle-aged and older patient groups. The diagnosis can be difficult, especially in the elderly patient population; this situation may lead to delays in the diagnosis $(15,16)$. For this reason, it would be more useful to determine the diagnostic tests based on age group and disease presentation before diagnosing a patient suspected as having AA. In our study, the majority of the cases were younger compared to elderly. Although there were more studies in the literature that showed more women are diagnosed with $\mathrm{AA}$, there were more males in the population with an AA diagnosis in our study (14).

In the literature, it was noted that US can be safely used for its high sensitivity values in AA diagnosis. In one study, the sensitivity of the US was given as $88 \%$, whereas it was given as $71.2 \%$ in another study $(17,18)$. Some studies with lower sensitivity rates have also been reported in the literature (14). The sensitivity was reported as $67.6 \%$ with the head-up US (13). Besides not having a high sensitivity, US has other limitations including its limited use in non-working hours and on weekends because a trained technician is not present (19). However, it is the method that should be preferably used first in children and the younger population because it can be done quickly, and it does not include any radiation (19-21). In our study, US sensitivity was found to be high; this rate is even higher in the young patient population. In our study, the level of sensitivity was found high in the young population. Therefore, US was more preferable in young patients who had symptoms possibly indicative of AA.

Sensitivity of CT in AA was between $83.3 \%$ and $100 \%$, which is higher than that of US $(14,18)$. The CT method, which is more sensitive compared to US, is usually used for older patients and for patients who are more likely to have complications $(19,22)$. In one study, the possibility of peritonitis and the length of hospitalization were found higher in the patient group where CT was preferred (22). Because of the possibility of malignancy in the elderly patient group, a CT scan is usually performed in the preoperative period. For this reason, CT should be preferred in these patients to avoid missing a diagnosis in a patient more likely to have complications and to avoid delay in the diagnosis. In our study, CT was more preferred in the elderly group and the sensitivity was found quite high.

Another group of patients cannot be diagnosed by either US or CT only. Literature reports suggest that CT can be used as a complementary method in patients who cannot be diagnosed with US (23). Even more interestingly, 5 (12.2\%) of the 41 patients with a negative CT in a study conducted with 104 patients noted that US reassessment helps avoid missing the diagnosis in patients who were found as AA-negative in a CT scan before the US (24). These studies showed that US and CT are complementary diagnostic tools. The necessity of using them together is usually helpful in a patient population with atypical presentation and therefore difficult to diagnose. In our study, approximately one in four patients who needed to have both US and CT scan and presented with symptoms suspicious of AA were diagnosed.

It is possible to make a faster AA diagnosis with US compared to $C T$, especially in the experienced centers that allow visualization of appendicitis (25). It is the first choice in the young population. CT should be preferred in elderly patients, although it delays the diagnosis compared to US. The time to diagnosis is even longer in the patient population in which both methods need to be used together.

\section{Study limitations}

In our study, we evaluated a well-defined patient group commonly encountered in emergency services where a large population is examined. Also, the need for diagnostic imaging methods used in different patient groups was assessed. The limitations of the present study include being single-centered and retrospective. However, because our hospital is a high-volume center, has an expert emergency department group working with the same clinical practices, and patient records are kept regularly, we think that our study presents valuable evidence.

\section{Conclusion}

As a result, US should be the first choice to be preferred in young and uncomplicated cases in the AA diagnosis, but it should not be preferred in elderly and patients with atypical presentations. It is very important to determine an age-related diagnostic algorithm for this disease, which is frequently encountered in emergency departments. More prospective studies are needed in this area. 
Ethics Committee Approval: Ethics committee approval was received for this study from the ethics committee of Medeniyet University Göztepe Training and Research Hospital.

Informed Consent: Written informed consent was obtained from patients who participated in this study.

Peer-review: Externally peer-reviewed.

Conflict of Interest: No conflict of interest was declared by the authors.

Financial Disclosure: The authors declared that this study has received no financial support.

\section{References}

1. Demircan A, Aygencel G, Karamercan M, Ergin M, Yilmaz TU, Karamercan A. Ultrasonographic findings and evaluation of white blood cell counts in patients undergoing laparotomy with the diagnosis of acute appendicitis. Ulus Travma Acil Cerrahi Derg, 2010; 16: 248-52.

2. Prystowsky JB, Pugh CM, Nagle AP. Current problems in surgery. Appendicitis. Curr Probl Surg 2005; 42: 688-742. [CrossRef]

3. Van Randen A, Bipat S, Zwinderman AH, Ubbink DT, Stoker J, Boermeester MA, et al. Acute appendicitis: meta-analysis of diagnostic performance of CT and graded compression US related to prevalence of disease. Radiology 2008; 249: 97-106. [CrossRef]

4. Gaitini D, Beck-Razi N, Mor-Yosef D, Fischer D, Itzhak OB, Krausz MM, et al. Diagnosing acute appendicitis in adults: accuracy of color Doppler sonography and MDCT compared with surgery and clinical follow-up. AmJ Roentgenol AJR 2008; 190: 1300-6. [CrossRef]

5. Ünlüer EE, Urnal R, Eser U, Bilgin S, Hacıyanlı M, Oyar O, et al. Application of scoring systems with point-of-care ultrasonography for bedside diagnosis of appendicitis. World J Emerg Med 2016; 7: 124-9. [CrossRef]

6. Inan $\mathrm{M}$, Tulay $\mathrm{SH}$, Besim $\mathrm{H}$, Karakaya J. The role of ultrasonography and Alvarado score in diagnosis of acute appendicitis. Ulus Cerrahi Derg 2011; 27: 149-53.

7. Jan YT, Yang FS, Huang JK. Visualization rate and pattern of normal appendix on multidetector computed tomography by using multiplanar reformation display. J Comput Assist Tomogr 2005; 29: 446-51. [CrossRef]

8. Anderson JE, Bickler SW, Chang D, Talamini MA. Examining a common disease with unknown etiology: trends in epidemiology and surgical management of appendicitis in California, 1995-2009. World J Surg 2012; 36: 2787-94. [CrossRef]

9. Kong VY, Bulajic B, Allorto NL, Handley J, Clarke DL. Acute appendicitis in a developing country. World J Surg 2012; 36: 2068-73. [CrossRef]
10. Toorenvliet BR, Wiersma F, Bakker RFR, Merkus JW, Breslau PJ, Hamming JF. Routine ultra-sound and limited computed tomography for the diagnosis of acute appendicitis. World J Surg 2010; 34: 2278-85. [CrossRef]

11. Alvarado A. A practical score for the early diagnosis of acute appendicitis. Ann Emerg Med 1986; 15: 557-64. [CrossRef]

12. De Castro SM, Unlu C, Steller EP, van Wagensveld BA, Vrouenraets BC. Evaluation of the appendicitis inflammatory response score for patients with acute appendicitis. World J Surg 2012; 36: 1540-5. [CrossRef]

13. Mallin M, Craven P, Ockerse P, Steenblik J, Forbes B, Boehm K, et al. Diagnosis of appendicitis by bedside ultrasound in the ED. Am J Emerg Med 2015; 33: 430-2. [CrossRef]

14. Chen KC, Arad A, Chen KC, Storrar J, Christy AG. The clinical value of pathology tests and imaging study in the diagnosis of acute appendicitis. Postgrad Med J 2016; 92: 611-9. [CrossRef]

15. Salahuddin O, Malik MA, Sajid MA, Azhar M, Dilawar O, Salahuddin A Acute appendicitis in the elderly; Pakistan Ordnance Factories Hospital, Wah Cantt. experience. J Pak Med Assoc 2012; 62: 946-9.

16. Bhullar JS, Chaudhary S, Cozacov Y, Lopez P, Mittal VK. Acute appendicitis in the elderly: diagnosis and management still a challenge. Am Surg 2014; 80: 295-7.

17. Hussain S, Rahman A, Abbasi T, Aziz T. Diagnostic accuracy of ultrasonography in acute appendicitis. J Ayub Med Coll Abbottabad 2014; 26: 12-7.

18. Ozkan S, Duman A, Durukan P, Yildirim A, Ozbakan O. The accuracy rate of Alvarado score, ultrasonography, and computerized tomography scan in the diagnosis of acute appendicitis in our center. Niger J Clin Pract 2014; 17: 413-8. [CrossRef]

19. Bhangu A, Søreide K, Di Saverio S, Assarsson JH, Drake FT. Acute appendicitis: modern understanding of pathogenesis, diagnosis, and management. Lancet 2015; 386: 1278-87. [CrossRef]

20. Kim SH, Choi YH, Kim WS, Cheon JE, Kim IO. Acute appendicitis in children: ultrasound and CT findings in negative appendectomy cases. Pediatr Radiol. 2014; 44: 1243-51. [CrossRef]

21. Karul M, Berliner C, Keller S, Tsui TY, Yamamura J. Imaging of appendicitis in adults. Rofo 2014; 186: 551-8. [CrossRef]

22. Ho TL, Muo CH, Shen WC, Kao CH. Changing roles of computed tomography in diagnosing acute appendicitis in emergency rooms. QJM 2015; 108: 625-31. [CrossRef]

23. Cağlayan K, Günerhan Y, Koç A, Uzun MA, Altınlı E, Köksal N. The role of computerized tomography in the diagnosis of acute appendicitis in patients with negative ultrasonography findings and a low Alvarado score. Ulus Travma Acil Cerrahi Derg 2010; 16: 445-8.

24. Jang KM, Lee K, Kim MJ, Yoon HS, Jeon EY, Koh SH, et al. What is the complementary role of ultrasound evaluation in the diagnosis of acute appendicitis after CT? Eur J Radiol 2010; 74: 71-6.

25. Drake FT, Flum DR. Improvement in the diagnosis of appendicitis. Adv Surg 2013; 47: 299-328.[CrossRef] 